\title{
Understanding and Managing Three-Dimensional/ Four-Dimensional Model Implementations at the Project Team Level
}

\author{
Timo Hartmann, A.M.ASCE ${ }^{1}$; and Raymond E. Levitt, F.ASCE ${ }^{2}$
}

\begin{abstract}
This paper introduces an extant, theoretical, social-psychological model that explains the sense-making processes of project managers confronted with a new technology to improve our understanding of project-based innovation processes. The model represents the interlinked processes through which project managers decide to implement new technologies on their projects according to the outcomes of these sense-making processes. The paper validates the model against observations gathered in four case studies of technology implementation on construction projects. Doing so, it assesses the general usefulness of the model to explain the success of technology implementation dynamics in project teams. The paper also derives a number of management suggestions from the model: for example, project managers should focus squarely on the immediate benefits of the technology in improving work processes on the project instead of focusing on long-term strategic firm or industry benefits.
\end{abstract}

DOI: $10.1061 /($ ASCE)CO.1943-7862.0000174

CE Database subject headings: Technology; Implementation; Decision support systems; Social factors; Case studies; Threedimensional models; Project management.

Author keywords: Technology; Implementation; Decision support systems; Social factors; Case reports.

\section{Introduction}

The construction industry is often depicted as slow to adopt information technologies (ITs). Lately, however, this negative perception of the industry has changed. Most large and mediumsized construction firms have successfully implemented ITs to manage company-wide finances and resources strategically across projects. In the past couple of years, InformationWeek has even ranked construction companies, such as Parsons Corp., among the top 100 innovators in their annual rankings documenting these innovation successes (Greenemeier 2005). Complementing these industry driven efforts, researchers have made great improvements in understanding innovation processes at the industry level accounting for the industry's fragmented and diverse structure (Taylor 2007; Taylor and Levitt 2007; Dubois and Gadde 2002; Gann and Salter 2000). However, despite all these successes, empirical studies at the project level still document great struggles with the adoption and effective use of IT applications to support the operational decision making of project managers (Hartmann et al. 2008; Galloway 2006).

Such an understanding of the dynamics at the project level during the implementation of new IT systems is, however, of

\footnotetext{
${ }^{1}$ Assistant Professor, Dept. of Construction Management and Engineering, Univ. Twente, P.O. Box 217, 7500 AE Enschede, The Netherlands (corresponding author). E-mail: t.hartmann@utwente.nl

${ }^{2}$ Professor, Dept. of Civil and Environmental Engineering, Stanford Univ., Stanford, CA 94305, USA. E-mail: ray.levitt@stanford.edu

Note. This manuscript was submitted on February 3, 2009; approved on November 16, 2009; published online on November 18, 2009. Discussion period open until December 1, 2010; separate discussions must be submitted for individual papers. This paper is part of the Journal of Construction Engineering and Management, Vol. 136, No. 7, July 1, 2010. CASCE, ISSN 0733-9364/2010/7-757-767/\$25.00.
}

essential importance. Research in project-based industries shows that practitioners need to explore new technologies on single projects before company executive research and development (R\&D) departments can disseminate them through the whole company (Brady and Davies 2004). Thus, the existing, strategic, top-down innovation understanding of the construction research community needs to be complemented by a better understanding of bottom-up implementation processes at the operational project level. This paper sheds light on these bottom-up dynamics that project managers face during the implementation of IT systems. It introduces a theoretical, social-psychological model developed by Hartmann (2008) that describes project-based bottom-up technology implementation processes. The model follows the organizational sense-making theory (Weick 1995) that explains how project team members understand how a new technology fits into their respective environment. In particular, the sense-making theory helps the model to describe how the project team members' beliefs about a technology influence their actions, while at the same time their actions inform their beliefs about the technology.

The paper provides evidence for the power of the model to explain successful or unsuccessful technology implementation processes using case study data from four construction projects. In this way, the paper is in the position to advance the understanding of project managers and R\&D professionals about bottom-up implementation processes. The paper also shows that project and R\&D managers can directly use the model to develop management recommendations for such implementations.

The paper is structured as follows: in the next section we introduce the extant bottom-up model of technology implementations briefly. The paper then shows how the model can explain the implementation dynamics on four construction projects. Next, the paper summarizes a number of recommendations for project and $R \& D$ managers that we directly derive from the enhanced under- 
standing of the implementation processes that the model allows us. The paper closes by discussing some of the limitations of this research and by offering new directions for future research endeavors.

\section{Bottom-Up Technology Implementation Theories and Projects}

To improve the understanding about bottom-up implementation processes, researchers first need an in-depth understanding of how construction project teams are organized. Traditionally, construction companies organize their workforces in projects that are detached from the formal hierarchy of the company. This hierarchical detachment, in turn, allows project team members to make the creative and timely decisions needed to produce the unique products of the built environment without the need to escalate decisions or possible problems to upper level managers. However, the same detachment, oftentimes, impedes the topdown implementation of new technologies, since upper level managers lack an in-depth understanding of local work processes and environments on the project level (Brady and Davies 2004). Therefore, it is important that project team members drive the implementation of new technologies from the bottom-up (Hartmann 2008; Brady and Davies 2004).

Models that describe such bottom-up processes need to account for four project and technology characteristics encountered by construction professionals on projects:

- ITs to support the decision making at the operational level (decision support systems) in project environments consist of "bundles of software, hardware, and processes" that can be used in different ways (Bidgoli 2003; DeSanctis and Poole 1994; Rice and Rogers 1980). Thus, it is often unclear how to configure software, hardware, and processes to support specific decision making tasks. This also means that the application of different configurations of software, hardware, and processes can often lead to the same outcome; alternatively, the use of the same configuration can result in different outcomes.

- Upper management cannot mandate the effective use of an IT system to support project-based decision making. Even though project team members have the opportunity to adopt and use the system, they can continue to make decisions without using it. There is no easy way for the upper management to control whether or not a system is used at all or used efficiently.

- Due to the high levels of reciprocal interdependence between many project tasks, project team members are dependent on information updates from other members (Thompson 1967; Gann and Salter 2000; Jin and Levitt 1996). Therefore, the successful implementation of a decision support system by a project team depends on a high level of integration of the system within the team.

- A project team is a temporary organization (Kreiner 1995). Therefore, project teams have only limited time to develop procedures about how to use a new decision support system. Further, how the members of the team define various attributes of the decision support system will vary throughout the project. A stable institutionalization (Scott 2001) of the use of a decision support system is thus unlikely.

The previously developed Grassroots model of technology implementation (Hartmann 2008) captures the socialpsychological dynamics of project teams during bottom-up IT implementation processes, accounting for these four project team

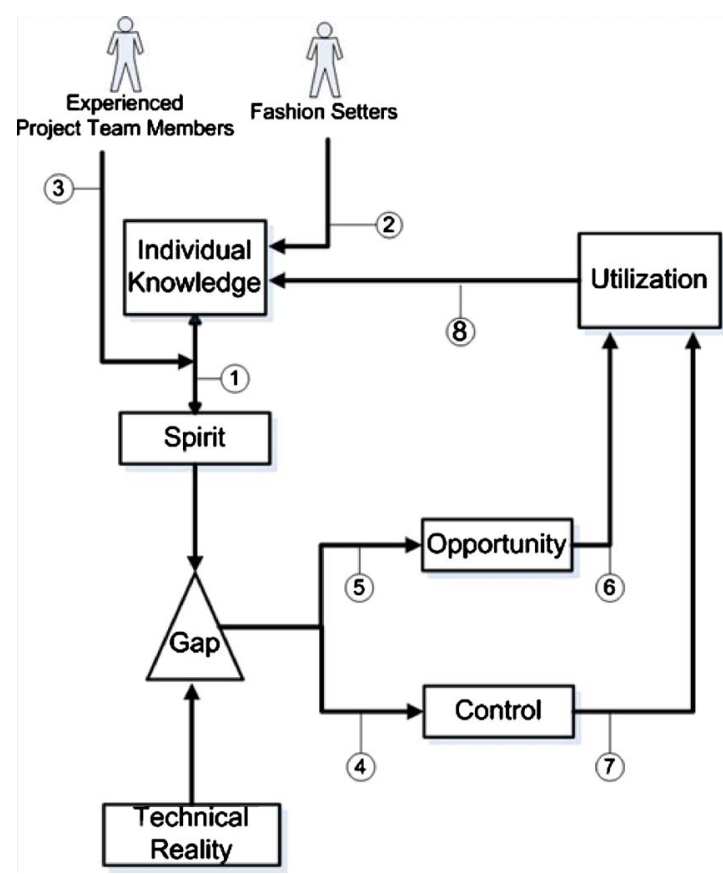

Fig. 1. Grassroots model of Hartmann (2008) of decision support system implementation by project team (callouts represent the propositions we refer to in the text)

characteristics. Fig. 1 illustrates the model and Table 1 summarizes the model's propositions. Using the sense-making theory (Weick 1995; Berger and Luckmann 1990), the model explains how members of a project team mutually generate the spirit of a decision support system that captures the outcomes of the project team members' sense-making processes about the system in the local project environment. This spirit describes the subjective characteristics of such systems as they are jointly perceived by the members of the project team (Majchrzak et al. 2000; DeSanctis and Poole 1994, Fig. 1-Proposition 1). The model asserts that this "spirit" is different from the "technical reality"-i.e., the "real" potential of the system to improve the work processes and the "real" technical knowledge that is needed to implement the system in the respective project environment. The model assumes that the two constructs of technical reality and spirit are never entirely identical, so that there exists a gap between them. The size of this gap is influenced by how accurately the spirit-the outcome of the project team's sense-making - describes the technical reality.

The model explains which actors influence the generation of the system's spirit. The model assumes that, when establishing the spirit, experienced project team members are able to shape the spirit more than relatively less experienced ones (Fig. 1-Proposition 3). The model, furthermore, assumes that during bottom-up implementations, actors who are not part of the project team-e.g., technology managers of the project team's company, consultants, or R\&D professionals-also influence the spirit (Fig. 1-Proposition 2). However, because of their lack of coercive power to influence the technical implementation of the system they have little influence on the technical reality on the project. In this way the model accounts for the characteristic that project teams are detached from the formal hierarchical power structure of the project-based company (Cohen and Bailey 1997). The model, therefore, assumes that project team members have to drive the technical implementation, while project team outsiders 
Table 1. Summary of the Grassroots Model's Propositions

Proposition 1 While making sense of a decision support system, project team members use rhetoric to integrate their individual knowledge to mutually establish the spirit of a decision support system.

Proposition 2 Using rhetoric, fashion setters influence the project team member's sense-making processes by updating individual knowledge and language.

Proposition 3 Using rhetoric experienced members of the project team have more influence on shaping the mutual spirit of the team.

Proposition 4 (1) A small gap between the spirit and the technical reality of the decision support system improves the project team members' perception of gaining control over the technology implementation.

(2) A large gap between the spirit and the technical reality of the decision support system causes project team members to perceive that they lose control over the technology implementation.

Proposition 5 (1) Project team members will only recognize existing objective opportunities of a decision support system, if the gap between the spirit and the technical reality of the decision support system is small.

(2) Project team members will not recognize existing objective opportunities a decision support system offers if the gap between the spirit and the technical reality of the decision support system is large.

Proposition 6 (1) The more project team members sense an opportunity to improve their work processes by using a decision support system, the more they try to maximize the possible benefits the system offers to improve their work routines.

(2) The more threatening the project team members sense that the implementation of a decision support system is to their established work processes the less likely they try to use the decision support system to its full benefits.

Proposition 7 (1) The more control over the implementation of a decision support system project team members sense, the more likely they are to maximize the benefits the system offers to improve their work routines.

(2) The less control over the implementation of a decision support system project team members sense, the less likely they try to use the decision support system to its full benefits.

Proposition $8 \quad$ Individual members of the project team will intensively update their knowledge about the system throughout the implementation because the implementation is characterized as a period of radical change.

have limited influence on the technical reality of the implementation. Following Abrahamson (1991, 1996), the model labels project team outsiders, therefore, "fashion setters." In summary, fashion setters can influence the team's spirit significantly and are, therefore, important to establish an initial understanding about the technology among the project team members.

The model asserts that the size of the gap between the objective technical reality of the system in use versus the subjective spirit that is established influences how project team members perceive the control they have over the implementation and how they perceive the opportunity that the system offers them to improve decision making tasks. The model asserts that project team members who, due to a small gap between the spirit and the technical reality, gain a feeling of control over the implementation of the system and who perceive that the system offers opportunities to improve their decision making tasks maximize the possible benefits the technology offers during implementation (Fig. 1-Propositions 4-7). In contrast, if the gap is large the model predicts that project team members conclude that they do not have control over the implementation and that they do not think that the system is an opportunity are likely to try to minimize the expected negative consequences of the technology implementation. The model predicts that in these cases project team members are not likely to utilize the new system and try to avoid using it as much as possible. Finally, the model proposes that the individual knowledge of the project team members influences how project team members utilize the system (Fig. 1-Proposition 8).

In summary, by focusing on characteristics specific to project teams the model is tailored to explain bottom-up technology implementations within the flat hierarchies existing on projects. To provide evidence for this claim, we collected data from four case studies on which construction project teams implemented a decision support system. The following sections describe the cases and how we collected data on them.

\section{Research Method}

To show the explanatory power of the model, the first writer conducted an ethnographic case study research on four construction projects in the United States that implemented systems to support decisions at the operational project team level. We theoretically sampled construction projects that produced different types of facilities and that implemented three-dimensional/fourdimensional (3D/4D) model-based decision support systems (Hartmann et al. 2008). The variance in facility types-we studied two hospitals, one road, and one bridge project-allowed us to explore how well the model can explain the implementation within different construction project settings. At the same time, we were able to compare the implementation across the projects well because all projects planned to implement the same 3D/4D model-based decision support system software. In general, such 3D/4D system software combines geometrical 3D computer-aided design (CAD) models of a project's physical facility with construction schedules of planned construction activities. In this way, they allow project managers to get a better understanding about spatial and temporal relations during the project planning activities. The four cases are summarized in Table 2.

The role of the first writer varied from project to project. On two projects he supported the project team with a specific technology implementation as a consultant; on one project he was a full blown member of the project team itself; and on one project he had a completely passive role, only interviewing and observing the project team members. This variability of involvement on the projects allowed us to get a set of unique insights into different 4D model-based decision support system implementations. On the project where the first writer passively observed the implementation we were able to collect and analyze data from an analytical distance. In this way it was possible for us to remain largely unbiased; however, it was not possible to gain as deep an understanding about the implementation as was possible on the projects the first writer was more directly involved as a participant of the implementation. During such direct participation, we were able to get deep insights into the problems and challenges that individual project team members faced (Jorgensen 1989, p. 61). The first writer's two different roles of participation, as a consultant and as a project team member, allowed us to analyze 
Table 2. Project Characteristics

\begin{tabular}{lccccc}
\hline Case & Racility & Role & $\begin{array}{c}\text { Days } \\
\text { on site }\end{array}$ & $\begin{array}{c}\text { Meetings } \\
\text { joined }\end{array}$ & $\begin{array}{c}\text { Team } \\
\text { size }\end{array}$ \\
\hline C1 & Highway & Consulting & 5 & 3 & 3 \\
C2 & Bridge & Consulting & 5 & 3 & 7 \\
C3 & Hospital & Project team & 15 & 8 & 7 \\
C4 & Hospital & Passive & 2 & 0 & 4 \\
\hline
\end{tabular}

${ }^{\mathrm{a}}$ We identified the project team size by directly asking the project team members.

the explanatory power of the model for $R \& D$ managers and project managers, the two practitioner groups this paper addresses. At the same time, however, our direct in-depth involvement also had two shortcomings. First, the direct involvement of the first writer might have caused him to be biased during the data analysis. To counteract such an unbiased analysis of data, the second writer of the paper critically reviewed the findings from an outsider's perspective (Bartunek and Louis 1996). Second, during the direct involvement the first writer influenced the outcomes of the 3D/4D system implementation. We acknowledge this shortcoming of our research method. However, it is quite common that 3D/4D system implementations are supported by either an outside consultant or an inside project champion. Thus, the first writer's direct involvement on the implementation processes as a consultant or project team member was not unusual for 3D/4D system implementations. Therefore, we think that the direct involvement did not significantly distort how the paper's findings represent 3D/4D model implementation processes in general.

The most important form of data we collected on the project stemmed from open-ended ethnographic interviews the first writer conducted with key project participants (Spradley 1979). While interviewing, the first writer started with a set of guiding questions; however, he followed these questions only loosely. We tried to allow informants to report about the technology implementation in their own language and move the interview in directions that they deemed to be important. The ethnographic style of our interviews enabled us to collect rich information that allowed us to understand the perspective of the individual project team members on the decision support system implementation from their points of view. From a data collection standpoint, the overall goal of the interviews was twofold. First, we tried to understand what information sources the project team members used to inform themselves about the decision support systems. Second, we tried to understand how the informants felt that the system could help them with their individual work and with the work of the whole project team. The first writer also asked the project team members whether their expectations had been met by the implementation at the point in time of the interview. For each of the project teams we identified informants using snowballing: we started each of the interviews by asking the informant to name the members of the project team. This allowed us to identify the ethnographic boundaries of the project teams as they were perceived by the teams' members. We tried to interview all project team members that we were able to identify in this way. However, some project team members refused to have interviews with us or did not respond to our interview request at all. Table 2 shows the ethnographic size of the project teams we identified and the number of interviews we were able to conduct with project team members.

To allow for triangulation of the interview data (Yin 2003; Miles and Huberman 1994) the first writer also collected data from multiple other sources. He observed how the project team members implemented the decision support system by spending time on the projects observing the daily work of the project team members and by joining meetings that were related to the implementation effort. He recorded findings in notebooks and summarized the observations from each day for each of the projects within a diary. He also collected any documents that were related to the $3 \mathrm{D} / 4 \mathrm{D}$ based decision support implementation such as meeting minutes, decision support input data, or e-mails. Table 2 summarizes the overall data collection effort on the case projects.

We analyzed the data following the case study method of Yin (2003). We stored transcripts of the interviews, the diaries and field notes, and all other documentation in a database using the qualitative data analysis software NVivo (Bazeley 2007). Using the qualitative data coding functionality of NVivo, we then formally coded the data. As we intended to provide evidence for an extant theoretical model and not to develop a new grounded theory ourselves, we did not start our coding effort with open coding to describe our test, but directly started with axial coding. During axial coding, we used three main categories that describe how informants gained knowledge about the 3D/4D system; the informants' feelings and knowledge about the 3D/4D technology; and reports of informants about the actual use of the 3D/4D system. In this way, axial coding helped us to get a first overview about the data and how it relates to the Grassroots model. We then continued with the theoretical coding of these three categories trying to directly match the propositions of the Grassroots model. Hereby, we tried to identify common themes that represented the team members' common spirit of the 3D/4D system on each of the projects. We also searched for chains of evidence that explained who was involved during establishing the common spirit. Further, we tried to identify chains of evidence that showed how the magnitude of the gap between the spirit of the 3D/4D system and its technical reality was related to whether the implementation of the system on the projects was successful or not. To calibrate the gap between the spirit versus the technical reality, we compared statements of project team members about the usefulness of the system for the whole project team with their assessments of how the system could help them perform their individual work. We assumed that the gap was small if individual project team members mentioned both project team benefits and individual benefits of the system during their interviews. We then compared these statements with our observations of the project team members' work practices and how they used the 3D/4D system. We stopped our theoretical coding effort after we coded all data according to the Grassroots models' proposition. As we did not intend to develop a new grounded theory, we did not try to reach theoretical saturation during the coding effort by developing new codes or categories.

To understand whether an implementation was successful we observed whether the system was used by the project team members to support their individual decision making while working on the project. We also followed up on our personal visits to the respective projects by calling key informants of the project a number of months later to confirm whether the system was then being used or not. Again we triangulated our assessments of 
project success with our observations and with other external documents about the project. The next two sections will describe our findings from the data analysis in detail.

\section{Generation of the 3D/4D Systems' Spirits}

The findings of the data analysis show that the project teams on each of the projects established a unique spirit of the 3D/4D system that emerged from the collective perceptions of the project team members. The team's spirit describes the way in which the team members collectively perceived the potential of the 3D/4D system to support decision making tasks and how the project team members believed they were able to implement the system. This provides evidence for Proposition 1 of the Grassroots model. Further, the data show how the generation of the spirit was influenced by fashion setters from outside the project team and by the experienced project team members. This is in line with Propositions 2 and 3 of the Grassroots model. The section will explain our findings about how each of the project teams generated the spirit of the 3D/4D decision support systems in detail using the concepts from the model. To allow the reader to follow our reasoning in relation to the case data, we also present example quotes from each of the projects that support these findings.

On Project C1, the project team had established a very strong spirit of the 3D/4D system. This is evident as all the informants agreed during the individual interviews on the possible benefits of the system and on the best way to implement the system. The project team believed that the $3 \mathrm{D} / 4 \mathrm{D}$ system mainly offered the opportunity to support the project team in communicating tasks to nonengineers:

"So this is a great tool in terms of communicating what we know to other people."

"It would be a powerful tool to communicate. We could show them how the project at point one, two, three, four looks."

"I think it will help a lot in terms of communicating our message to the public."

The following quote from the interviews, however, also shows that the project team agreed that the use of the system to support internal decision making tasks would be limited: "Internally we will not need it as we are all engineers that are pretty good at looking at a set of schematic drawings." Due to this perception of the limited scope of the software on the project, the members of the project team were also of the opinion that outside consultants should mainly drive the implementation of the systems, while the project team members only used the output of the work of these consultants for visualization purposes. The data additionally show the strong influence of outside fashion setters on the spirit. Informants mentioned in their interviews that they first heard of, and got most of their information about, the 3D /4D system from a fashion setter (abbreviated as G. in the below quotes) within the company's marketing department and from an outside consulting company:

"Somebody showed me a video of the system that came out of the consulting company."

"Probably, maybe a year ago, when G. (nonproject team member but employee of the firm) showed me a video."

The findings from this project do not show that experienced project managers were the persons who influenced the generation of this spirit.

On Project $\mathrm{C} 2$, the evidence of a common spirit was not as strong as on Project C1. Most of the project team members agreed that the main opportunity the system offered was its potential as a presentation tool:

"Here it is really going to be a detailed presentation tool."

"This is what clients are expecting today. You go in and blow them away with a video presentation of what it will look like during construction."

"Basically having the 4D model gives them (the clients) a way to view the project instead of flat renderings or just the animation."

"It would be helpful for the general public and these meetings we have showing them what phasing we have."

However, at least one informant was not aware of the scope of the system implementation: "I am not sure, however, what the scope on this project is. I might as well get informed." Our data from this project provide limited evidence for the influence of fashion setters on the spirit. In contrary, our findings show that the two most experienced project team members (abbreviated as D. and J.) seemed to be strongly influencing the project team-wide spirit:

"I learned it from D. and we talked about it here on the project."

"D. was actively involved in meetings and communications about the system."

"D. and J. have the most experience of managing projects."

On Project C3 the project team members' spirit was again very strong with respect to the perceived opportunities. Three of the four interviewed project team members agreed that the main benefit of the technology is its potential to support coordination between different trades:

"Now we have the software and it looks like it is an integral part to coordinate. I do not know how one would coordinate previously; the software makes it so much easier."

"We have to coordinate elevations to get our piping in so that it does not hit and that is where the software program is going to come in handy."

"During coordination, by doing this we are not going to have those hundred and fifty thousand change orders because we figure it out now."

The common spirit with respect to the perceived control over the implementation was less strong. One informant perceived a very high control over the implementation, so that he even suggests improvements: "I think in the future it would be best to have a server that everybody could be dialing in and have the coordination meeting over the computer where everybody can see what the other person is doing or looking at."

However, two other informants seemed to still struggle with how best to use the technology within the local project context:

"I am begging on this to be working." 
"To use the software I have to meet with my CAD person and we work together on inputting."

Project C3 shows a very strong influence on the spirit from experienced project team members (D. and C.):

"We were watching D. and picked up some things of how to operate the software; I never had any training."

"On this project I first heard of the software from D. and from C."

"It was a learning curve. D. and me were meeting every Monday."

"C. basically taught me what is possible and set some expectations."

Our data triangulation with notes from direct observations shows that D. and C. are experienced project team members and thus the model's Proposition 3 explains well what happened on Project C3. The data from this project do not show much influence of outside fashion setters on the project team's spirit. Only one informant mentions the influence of outside fashion setters during his response to our question about from whom the informant received information about the technology: "Actually in one of the meetings they brought someone in from a company and they went through a couple of tricks on how to use the software."

Project $\mathrm{C} 4$ supports the argument that project teams establish a common spirit that describes a decision support system. Informants on the project repeatedly stated that the system offered them the possibility to coordinate construction work and ultimately that the use of the system saved project resources such as time and money:

"... all that front end work, all these hours of coordination; it is a lot cheaper than screwing something up in the field."

“... so much time, so much time, probably over $100 \%$ cut in time."

Furthermore, the project team was able to build up a common spirit about how easy the decision support system is to use:

"I think it is minimal training and just by being accustomed to CAD you know the basics of the software, the basics of it."

"Once we got the full scope of how this thing works and I started getting into it using it on the project, I'll beg for it on any project from now on."

Again the spirit was influenced by fashion setters, three of the four informants stated that they learned the characteristics of the decision support system from company-wide technology managers (D. and A.):

"I worked with D. and A. and they were really motivated to use it and it sounds like a great idea."

"D., A., they sat down at the beginning of the project ... how we are going to use 3D/4D."

Additionally, the interview data show that project team members were largely influenced by one of their peers (G.):
"Yes, G. is pretty up to date on that technology. He is the one that actually was our guy who would sit with the engineers in the trailer next door and going through designing this with $3 \mathrm{D} / 4 \mathrm{D}$."

"G. is by far the best at 3D/4D modeling."

\section{Gap between Spirit and Technical Reality, Opportunity, Control, and Utilization}

The next two subsections describe our findings about the gap that exists between the spirit of the 3D/4D system and the technical reality. These subsections also show how the magnitude of this gap influenced how project team members perceive the control they have over the implementation of a decision support system and how much opportunity they feel the system offers them. Finally, the section relates these findings to the project success as the dependent variable. In this way these case data support the model's propositions, which explain a successful or unsuccessful technology implementation by analyzing the gap between the spirit and the technical reality. The section starts by describing the findings from the unsuccessful projects and then proceeds to analyze the findings from the successful ones. Again we provide exemplary quotes from our interviews to illustrate our findings.

\section{Unsuccessful Projects}

The findings from the two unsuccessful projects show a large gap between the spirit of the technology and the reality on the project. Our data show a gap with respect to both aspects of the spirit described above: the possible benefits of the system and how to implement the system. However, despite the apparent gap with respect to both aspects, on Project C1 the gap was mainly evident in how much opportunity the team members believed the decision support system offered versus the objective technical potential of the system. In contrast, on Project C2, the gap was mainly evident with respect to how the project team members planned to implement the system locally.

As the previous sections show, the project team on Project $\mathrm{C} 1$ mainly perceived the $3 \mathrm{D} / 4 \mathrm{D}$ system as a visualization tool with little potential to support the decision making of the project team members. Triangulating the interview statements with the observations from the project, however, shows that the project team could have also benefited significantly by using the system to support the coordination of project team members. An example episode that is recorded in our field notes shows this gap between the spirit and the technical reality on this project. During the evaluation of whether to use the system or not, the project team decided to generate a visual simulation of the construction sequence of a number of train tracks that needed to be moved to a new position. Due to a lack of internal experience the project team asked a number of specialists from the company's marketing department to create the visualization. One of the project team members had previously worked on this issue and had developed a construction sequence in his mind. Therefore, the visualization company consulted this project team member during the working session to generate the simulation. However, as the project team member had planned the sequence a number of months ago, the project team member had forgotten most of the details of the sequence and had to reengineer the sequence during the working session. It is not surprising that it took the project 
team member around $30 \mathrm{~min}$ to reconstruct the sequence before the visualization specialist was able to start creating the visualization of it.

Right after this work meeting during an informal conversation, the engineer agreed that if he had used the 3D/4D system to plan the sequence previously, he would have been able to initially create the sequence faster. More importantly, he also agreed that it would have been possible for him to easily reconstruct the sequence a number of months later by using the visualization possibilities of the $3 \mathrm{D} / 4 \mathrm{D}$ system. Therefore, he agreed that the possibility to create and store sequence simulations with the 3D/4D system could offer great potential for him to save time and better support his decision making.

However, in an interview conducted with the project team member 3 weeks later, he stated (according to the prevailing spirit on the project): “. . f for me it would be probably more work at least in the short term if my project team would implement the 3D/4D system."

This episode clearly supports the model's proposition that a large gap between the spirit and the technical reality causes project team members to perceive that a decision support system that is implemented does not offer an opportunity to improve decision making tasks but poses a threat to existing work conditions ("would be probably more work"). Proposition 5 of the model can explain such dynamics on projects. Furthermore, Proposition 6 can explain this episode well by showing how project team members refuse to use a technology if they perceive it as a threat to their existing work conditions.

Project $\mathrm{C} 2$ is a great example of how a large gap between the spirit of the system and the technical reality on the project with respect to how best to implement the use of the system on the project caused the project team members to perceive a lack of control over the implementation. The project team of Project C2 had vast experience with the use and the creation of 3D models. During the interviews informants mentioned that they had used $3 \mathrm{D} / 4 \mathrm{D}$ systems on previous projects:

"I learned it first in 1988 and then we talked about it here on the project."

"Actually we used something like it on (a previous project)."

Additionally, our observations showed that the experienced project team members were very proficient in using the 3D/4D software that they planned to use on the project. Informants stated that project team members had significant experience in CAD to create $3 \mathrm{D}$ models and that they planned to hire additional CAD resources. Despite all this internal experience, the project team decided to outsource the production of the 3D/4D models to an outside visualization agency. The data show that the project team members chose to outsource the efforts because they believed, according to the spirit on this project, that they did not have the internal capabilities to create 3D models by themselves: "...we simply do not have the in-house resources to do it."

The following observed episode further illustrates this large gap between the perceived inability to generate the 3D models internally and the technical expertise of the project team well. In one of the early efforts to generate the 3D model that the project team planned to use to support their work, the 3D modeler from the visualization department seemed to have significant problems generating a model that represented the right information as the needed information was contained in a number of separate construction drawings. Consequently, the experienced CAD project team members started to support the 3D modeler from the visualization company. The following excerpt from an e-mail of the project team member shows this in detail: "I know that you are working with CAD and PDF files, which may take you more time to develop the model, but the information is there. I think you should start development from existing information that you have and then develop the proposed structure."

This quote shows the existing knowledge of the project team with the $3 \mathrm{D} / 4 \mathrm{D}$ modeling process. It can, therefore, serve as a great indicator that the project team might have been able—and maybe even better off-by organizing and conducting the 3D modeling effort internally. However, the team still decided to outsource the efforts which caused problems like the one we describe above.

This underestimation of the team's technical abilities, in turn, caused the project team to feel that they had little control over the implementation. Consequently, the project team tried to gain control over the 3D modeling effort back by working more closely together with the 3D modeler. For example, the project team decided that the 3D modeler of the visualization company had to fly to the project site that was more than 2,000 miles (approx 3,200 $\mathrm{km}$ ) away from the office of the visualization specialist to discuss a number of issues. In one of the meetings with the 3D modeler the project team then decided to specify exactly the information that the 3D modeler should use for generating the 3D models, which caused a significant amount of work for the project team members. However, all these efforts to regain control failed and the project team never used the 3D/4D system as anticipated. Concluding, we suggest that the implementation on this project would have been more successful if the project team had been more realistic about their internal 3D modeling capabilities and had started to generate the 3D models itself. In this way the project team would have gained more control over the implementation. More control, in turn, would have the enabled the project team to utilize the $3 \mathrm{D} / 4 \mathrm{D}$ system as intended.

The examples above show that the Grassroots model can explain the findings from the two unsuccessful projects well. In the next subsection we will analyze how well the model can describe the implementation on the three successful projects.

\section{Successful Projects}

Project C3 applied the 3D/4D technology successfully to support the coordination of the different project team members during meetings. The first writer visited the project three times to join such coordination meetings and project participants reported in private conversations that the use of the $3 \mathrm{D} / 4 \mathrm{D}$ model was very helpful. The project team members' use closely followed the common spirit that we described in the previous subsection that described the main potential of the 3D/4D system to actually support the ongoing coordination of the project team members. Thus, the model can greatly explain what happened on Project C3 with its concept of the small gap between the spirit and the technical reality and how the small gap causes the project team members to perceive control over the implementation and perceive that the technology offers an opportunity to improve the project's work processes. Accordingly the model explains well why the project team used the model successfully and why the implementation turned out to be successful.

The dynamics of Project C4 can also be well described by how a small gap between the spirit and the technical reality leads to a successful technology implementation. Several statements from 
the informants on this project provide evidence for the small gap between the spirit versus the technical reality on this project:

"During the sign off period the use of the model was exactly what we expected."

"We expected to have everything $100 \%$ coordinated in the model, and we are just shy of that."

This small gap is a good indicator, why the project team members on this project developed a spirit of the technology that is characterized by high levels of perceived opportunity that the 3D/4D models offers, and control of its mode of implementation. Furthermore, Project C4 was characterized by a high level of utilization of the 3D/4D system: "Any single individual on the project was using the $3 \mathrm{D} / 4 \mathrm{D}$ system, and continues to use the 3D/4D system, probably every day of the week."

How the project team members used the 3D/4D system closely resembled the team's spirit that was evident from the meetings. Thus, we find additional evidence for the propositions of the model, which attribute this high level of utilization to the fact that the gap between the spirit and the technical reality was small on this project, and that this small gap, in turn, fostered the project team members' feelings of control and opportunity.

Additionally, Project C4 also shows strong evidence for the iterative nature of the sense-making processes that the Grassroots model asserts in Proposition 8. A number of statements from the project's informants show that project team members updated their individual knowledge by directly using the 3D/4D system:

"I learned it by kind of tinkering around."

“...at first I pushed against it, I did not want to do it; all the old men-a lot of us-do not like changing. But it is like, once we got the full scope of how these things work and I started getting into it using it on the project, I will ask for it on every project from now on."

\section{Discussion and Limitations of the Findings}

The findings from our data analysis provide additional evidence to corroborate that the Grassroots model of decision support system implementations explains the sense-making process of project teams during the implementation of the 3D/4D technology well. In particular, the model is able to explain how project teams generate the spirit of the 3D/4D systems on the projects accounting for input from fashion setters from outside the project and from more experienced project team members. Further, the model can explain how the spirit, and in particular, the gap between the spirit and the technical reality influences the individual sensemaking process of the project team members and influences their decisions of how to use the 3D/4D systems. Tables 3 and 4 summarize the evidence that the four cases studies provide for the Grassroots model.

The four case studies further strengthen our claim that the Grassroots model describes the sense-making processes of team members regarding 3D/4D systems. However, from our data analysis we cannot claim that the findings for the cases provide evidence for the generality of the model with respect to the implementation of other decision support systems on construction projects. Additionally, all projects were relatively large projects, and the focus of the interviews and observations was on a relatively small part of the overall project. Future research should, therefore, seek to provide additional evidence for the explanatory
Table 3. Summary of the Case Evidence for the Grassroots ModelGeneration of the Spirit

\begin{tabular}{lccc}
\hline & & \multicolumn{2}{c}{ Influence on spirit } \\
\cline { 3 - 4 } Project & Spirit & $\begin{array}{c}\text { Fashion } \\
\text { setting }\end{array}$ & $\begin{array}{c}\text { Project } \\
\text { team } \\
\text { members }\end{array}$ \\
\hline C1 & Yes & Yes & No \\
C2 & Yes & Yes & Yes \\
C3 & Yes & No & Yes \\
C4 & Yes & Yes & Yes \\
\hline
\end{tabular}

power of the Grassroots model on small and midsized projects and for larger organizations than the small project teams on these four large projects. Additionally, future research needs to evaluate how well the model applies to different stages during the implementation of technologies by conducting longitudinal studies. We suggest that future research should focus on providing support for the generality of the model by further operationalizing the propositions of the model to allow quantitative survey research. In the long run, such an operationalization of the propositions will also allow researchers to begin to quantify the relations between the constructs. For example, it will be interesting to see how some of the overlapping constructs in our propositions, such as the perceived control and opportunity, influence each other in greater detail.

Another limitation of the study is that it does not look at how different project characteristics directly influence the implementation success. At the outset, for example, it is striking that the two hospital projects successfully implemented the 3D/4D model, while the two infrastructure projects failed to do so. The question remains open how well the 3D/4D technology that all four projects implemented is suited to support infrastructure projects at all. However, one part of the sense-making processes that the model explains is that project team members try to understand whether a technology is suited to support a specific project context or not. In particular, the model predicts that if project team members come to the understanding that the technology offers little opportunity within a specific project context they will not utilize the technology. In this way the Grassroots model offers a first starting point for future research to look at the influence of different project characteristics on the implantation of new technologies. Nevertheless, we suggest that researchers try to replicate the findings of this paper on future case studies to explore the effects of different project characteristics on the sense-making processes during the implementation of new technologies.

In summary, from a theoretical viewpoint, the findings from these four cases provide supportive evidence for the propositions in the Grassroots model and thereby serve as a stepping stone for understanding the sense-making processes of project team members at the operational level of a project during the implementation of a decision support system better. Additionally, the findings of this study can help project and technology managers to understand the social-psychological dynamics on their projects better. This enhanced understanding, in turn, can help those managers to improve the implementation of decision support systems on their projects. We show the power of the Grassroots model to improve implementation practice by offering a number of tentative recommendations for managers that are directly derived from the Grassroots model in the following section. 
Table 4. Summary of the Case Evidence for the Grassroots Model—Gap between Spirit and Technical Reality, Opportunity, Control, and Utilization

Feelings of

\begin{tabular}{|c|c|c|c|c|c|c|c|c|}
\hline Project & Gap size & Control & Proposition $4^{\mathrm{a}}$ & Opportunity & Proposition $5^{\mathrm{b}}$ & Utilization & Proposition $6^{\mathrm{c}}$ & Proposition $7^{\mathrm{d}}$ \\
\hline $\mathrm{C} 1$ & Large & Not applicable & No & Little & Yes & No success & Yes & No \\
\hline $\mathrm{C} 2$ & Large & Little & Yes & Not applicable & No & No success & No & Yes \\
\hline $\mathrm{C} 3$ & Small & Strong & Yes & Strong & Yes & Success & Yes & Yes \\
\hline $\mathrm{C} 4$ & Small & Strong & Yes & Strong & Yes & Success & Yes & Yes \\
\hline
\end{tabular}

a(1) A small gap between the spirit and the technical reality of the decision support system improves the project team members' perception of gaining control over the technology implementation; (2) a large gap between the spirit and the technical reality of the decision support system causes project team members to perceive that they lose control over the technology implementation.

${ }^{b}(1)$ Project team members will only recognize existing objective opportunities of a decision support system, if the gap between the spirit and the technical reality of the decision support system is small; (2) project team members will not recognize existing objective opportunities a decision support system offers if the gap between the spirit and the technical reality of the decision support system is large.

${ }^{c}(1)$ The more project team members sense an opportunity to improve their work processes by using a decision support system, the more they try to maximize the possible benefits the system offers to improve their work routines; (2) the more threatening the project team members sense that the implementation of a decision support system is to their established work processes the less likely they try to use the decision support system to its full benefits.

d(1) The more control over the implementation of a decision support system project team members sense, the more likely they are to maximize the benefits the system offers to improve their work routines; (2) the less control over the implementation of a decision support system project team members sense, the less likely they try to use the decision support system to its full benefits.

\section{Recommendations of How to Manage Bottom-Up Implementations}

As Table 1 summarizes, the paper's first writer's involvement on the four case projects was either as an outside consultant, a project team member, or a pure observer. The first writer's role as an outside consultant - or in the language of this paper, as a fashion setter-enables us to develop a number of recommendations for other fashion setters directly from the model. These recommendations are intended to help a project team to implement a new 3D/4D technology or other decision support system. Additionally, his role as project team member helped us to develop recommendations of how project managers can manage implementations better, again by using the improved insights of the now further validated Grassroots model. We begin with recommendations for project managers and conclude the section with recommendations for fashion setters.

\section{Recommendations for Project Managers}

First, and most important, project managers that intend to implement a new decision support system must be sure to assess the benefits of the decision support system in immediately improving their project's work processes realistically. This recommendation contrasts with practice on most of today's implementation efforts that promise a large strategic benefit for the project team's whole company or even the construction industry over the long term. While it is important to have such high level goals, it is critically important to assess the potential benefits of a decision support system realistically at the project level. Only in this way are project team members able to establish a spirit that closely represents the technical reality on the project, and project team members will perceive that the system offers them benefits to improve their work processes. The same holds for the assessment of the technical expertise existing in the respective project team and the technical expertise that is needed to implement the decision support system. Only a realistic assessment of what is needed to implement the decision support system on the local project can ensure that the technical reality and the spirit is aligned and project team members start to feel control over the implementa- tion. To enable project team members to assess a decision support system thoroughly, project leaders, of course, need to plan and free up necessary resources for those project team members. Additionally, to foster the development of a spirit among project team members, project leaders need to make time available for project team members to discuss the decision support system implementation formally and informally.

While assessing the potential of the decision support system and the technical expertise required implementing the system, it is not sufficient to rely on information from outside the project team. Project teams usually work in complex frequently changing environments and information from outside the project context about the system will not reflect the complex project-specific context. Project teams need to explore the potential benefits of the technology on their specific project themselves; they cannot solely rely on standardized implementation guidelines or training programs developed for other contexts. Managers should, therefore, plan to implement decision support systems through iterative cycles of learning. Project teams should focus on easily reachable goals first and only slowly improve the sophistication of the local system implementation. Such an iterative implementation of learning by doing, in turn, will have the side effect that the project team's understanding about the technical expertise that is needed to implement the system remains close to the technical reality. In this way, project teams can choose next implementations steps that are realistically reachable with the existing technical expertise and thus project team members will not lose their perception of control over the implementation.

A realistic expectation about the expertise that project teams need to implement a decision support system also helps to manage the project team's recruiting strategies. In this way, project teams can bring knowledgeable and experienced project team members on board who can support the implementation and reduce the reliance on external fashion setters. This is important as the findings from the cases and the model itself imply that a too strong reliance on outside consultants will often not lead to a sustainable implementation. This is because outside consultants lack the required in-depth understanding of the prevailing local project conditions. Therefore, while outside consultants are important to build up initial knowledge about a new technology, the model predicts that they will only be able to shape the spirit and 
not the technical reality according to the local project requirements. Hence, it is likely that a strong reliance on project team outsiders will lead to a large gap between the spirit and the reality. The unsuccessful Project 2 with its heavy reliance on outside consultants can serve as an example for this kind of negative implementation dynamic. Nevertheless, fashion setters are an important part of the sense-making process during a technology implementation. The next session, therefore, summarizes a number of recommendations for fashion setters.

\section{Recommendations for Fashion Setters}

It is of the utmost importance that project team members drive the implementation of decision support systems in the way described above. At the same time, fashion setters also need to play a significant role during bottom-up decision support system implementations. Fashion setters make an important contribution to shaping the knowledge about the decision support system of the project team members. Project team members will only engage in change if they understand it (Ford and Ford 1995). Without Proposition 3, the model would represent a closed knowledge loop without the possibility of influencing a decision support implementation from outside the project team. Outside influence is important because outside fashion setters usually understand the features of the decision support system well, since they have knowledge about the implementation of the system on other projects. They can use this knowledge to create a positive attitude on the part of the project team members. This not only leads to the team's initial decision to implement the decision support system, but also improves the understanding of the team members about the decision support system. Thus, while fashion setters often widen the gap between spirit and technical reality during the implementation, they are important because they increase the project team's knowledge about different decision support systems that might have the potential to improve work processes.

In line with the above, construction companies should, therefore, establish a core group of very knowledgeable technology fashion setters that have knowledge about a variety of different decision support systems and how project teams can apply them within different environmental settings. These fashion setters then need to work closely with the various project teams of the company, supporting the members of the teams during their sensemaking processes. As part of their support, the fashion setters need to focus specifically on improving the decision making capabilities of the respective project team with the decision support system and not on implementing the decision support systems and processes in ways that are standardized for all projects of the company. In this way the fashion setters balance two contrasting needs: (1) evangelizing a decision support system to reach initial acceptance by the project team members; and (2) influencing the subjective spirit of the project team so that it closely matches the objective technical reality about the decision support system during implementation. Additionally, fashion setters can support the project team with their decisions of which decision support systems to implement and how to utilize them within the short time frame available on a project.

From their experiences on each of the supported projects, the fashion setters can then start to extract the lessons learned during one implementation and integrate them into a company-wide knowledge base as, for example, described by Brady and Davies (2004). Using this knowledge base, other project teams can support their sense-making processes by using prior implementation teams' lessons learned as ideas for improving the implementation of a decision support system in its local environment (Smeds et al. 2003). The fashion setters can then slowly and iteratively generalize use scenarios that have supported a number of different project teams and, in this way, iteratively develop standardized guidelines for the whole company.

\section{Conclusions}

This paper provides new evidence from four case studies that the Grassroots model of decision support system implementation (Hartmann 2008) can explain bottom-up 3D/4D system implementations on construction projects. The model is especially suited to explain two important influences on such implementations. First the model can explain who influences the team's knowledge about the system's technology and how the project team comes to perceive the possibilities the system offers. The cases analyzed in this paper demonstrate that fashion setters and experienced project team members-incorporated in the propositions of the Grassroots model-influence the common knowledge of the project team and can help to explain real world implementation dynamics related to these actors. Additionally, the case data reinforce the model's propositions about how individual project team members arrive at a decision to use the system, by assessing the amount of control they exert over the implementation, and the immediate usefulness of the system. Overall, the paper provides confirmatory evidence that the model explains the microbehaviors of team members and the outcomes of decisions support implementations. In this way, the model can help project and R\&D managers arrive at a better understanding of such implementations and guide them to secure more successful outcomes.

Beyond showing the usefulness of the model to explain decision support system implementations, the paper also derives a number of recommendations of how managers can implement decision support systems more successfully on projects. In particular, the paper suggests that project team managers need to drive the implementation of the software directly and should not rely too extensively on project team outsiders. Along the same lines, the paper suggests that project team outsiders who want to support the implementation of a decision support system must specifically consider the local project team's environment and work closely together with the project team during the implementation.

In summary, we believe that the Grassroots model presented in this paper can help R\&D and project managers understand the dynamics of decision support system implementations on projects better. In the long run, we hope that this enhanced understanding will lead to more sustainable decision support system implementations on construction projects. More sustainable implementations, in turn, can enable the construction industry as a whole to better leverage the potential that decision support systems offer for improving the industry's overall productivity.

\section{Acknowledgments}

We would like to thank the project team members that helped us as informants and supported us during our data collection efforts. Further, we would like to thank Martin Fischer, John Haymaker, Geert Dewulf, Kristian Kreiner, and the two anonymous reviewers for their valuable comments on earlier drafts of this paper. 


\section{References}

Abrahamson, E. (1991). "Managerial fads and fashions: The diffusion and rejection of innovations." Acad. Manage. Rev., 16(3), 586-612.

Abrahamson, E. (1996). "Management fashion." Acad. Manage. Rev., 21(1), 254-285.

Bartunek, J. M., and Louis, M. R. (1996). Insider/outsider team research, Sage Publications, Thousand Oaks, Calif.

Bazeley, P. (2007). Qualitative data analysis with NVivo, SAGE, Los Angeles.

Berger, P. L., and Luckmann, T. (1990). The social construction of reality: A treatise in the sociology of knowledge, Anchor Books, New York.

Bidgoli, H. (2003). Encyclopedia of information systems, Academic Press, San Diego.

Brady, T., and Davies, A. (2004). "Building project capabilities: From exploratory to exploitative learning." Organ. Stud., 25(9), 16011621.

Cohen, S. G., and Bailey, D. E. (1997). "What makes teams work: Group effectiveness research from the shop floor to the executive suite." J. Manage., 23(3), 239-290.

DeSanctis, G., and Poole, M. S. (1994). "Capturing the complexity in advanced technology use: Adaptive structuration theory." Org. Sci., 5(2), 121-147.

Dubois, A., and Gadde, L.-E. (2002). "The construction industry as a loosely coupled system: Implications for productivity and innovation." Constr. Manage. Econom., 20, 621-631.

Ford, J. D., and Ford, L. W. (1995). "The role of conversation in producing intentional change in organizations." Acad. Manage. Rev., 20(3), 541-570.

Galloway, P. D. (2006). "Survey of the construction industry relative to the use of CPM scheduling for construction projects." J. Constr. Eng. Manage., 132(7), 697-711.

Gann, D. M., and Salter, A. J. (2000). "Innovation in project-based, service-enhanced firms: The construction of complex products and systems." Res. Policy, 29, 955-972.

Greenemeier, L. (2005). Builders growing fond of IT, slowly, InformationWeek, Sept. 19, 2005, 1056, ABI/INFORM Global, 108.

Hartmann, T. (2008). "A Grassroots model of decision support system implementations by construction project teams." $\mathrm{Ph} . \mathrm{D}$. dissertation,
Dept. of Civil and Environmental Engineering, Stanford Univ., Stanford, Calif.

Hartmann, T., Gao, J., and Fischer, M. (2008). "Areas of application for 3D and 4D models on construction projects." J. Constr. Eng. Manage., 134(10), 776-785.

Jin, Y., and Levitt, R. E. (1996). "The virtual design team: A computational model of project organizations." Comput. Math. Organ. Theory, 2(3), 171-195.

Jorgensen, D. L. (1989). Participant observation: A methodology for human studies, Sage, Beverly Hills, Calif.

Kreiner, K. (1995). "In search of relevance: Project management in drifting environments." Scand. J. Manage., 11(4), 335-346.

Majchrzak, A., Rice, R. E., Malhotra, A., King, N., and Ba, S. (2000). "Technology adaptation: The case of a computer-supported interorganizational virtual team." MIS $Q ., 24(4), 569-600$.

Miles, M. B., and Huberman, A. M. (1994). Qualitative data analysis: An expanded sourcebook, Sage, Newbury Park, Calif.

Rice, R. E., and Rogers, E. M. (1980). "Reinvention in the innovation process." Knowledge, 1(4), 499-514.

Scott, W. R. (2001). Institutions and organizations, Sage Publications, Thousand Oaks, Calif.

Smeds, R., Haho, P., and Alvesalo, J. (2003). "Bottom-up or top-down? Evolutionary change management in NPD processes." Int. J. Technol. Manag., 26(8), 887-902.

Spradley, J. P. (1979). The ethnographic interview, Holt, Rinehart and Winston, New York.

Taylor, J. E. (2007). "Antecedents of successful three-dimensional computer-aided design implementation in design and construction networks." J. Constr. Eng. Manage., 133(12), 993-1002.

Taylor, J. R., and Levitt, R. E. (2007). "Innovation alignment and project network dynamics: An integrative model for change." Proj. Manage. J., 38(3), 22-35.

Thompson, J. D. (1967). Organizations in action: Social science bases of administrative theory, McGraw-Hill, New York.

Weick, K. E. (1995). Sense making in organizations: Foundations for organizational science, Sage Publications, Thousand Oaks, Calif.

Yin, R. K. (2003). Case study research: Design and methods, Sage, Thousand Oaks, Calif. 